\title{
DESENVOLVIMENTO E DIREITOS HUMANOS. MARCAS DE INCONSTITUCIONALIDADE NO PROCESSO BELO MONTE
}

\author{
Fernanda Cristina de Oliveira Franco e Maria Luiza Pereira de Alencar Mayer Feitosa
}

DEVELOPMENT AND HUMAN RIGHTS. MARKS OF UNCONSTITUTIONALITY IN BELO MONTE PROCESS

\section{RESUMO}

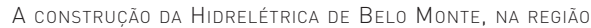
NORTE DO BRASIL, APRESENTA-SE COMO CAMPO DE REFLEXÕES SOBRE A QUESTÃO DO DESENVOLVIMENTO, RELEVANDO A NECESSIDADE DE ESTE SER ENCARADO EM SUAS DIMENSÕES PLURAIS E CONCRETIZADO POR VIAS DEMOCRÁTICAS. A ANÁLISE dos chamados Grandes Projetos de InVestimento, PARTICULARMENTE OS DO SETOR DA GERAÇÃO DE ENERGIA, PERMITE PERCEBER COMO DIREITOS HUMANOS E DESENVOLVIMENTO ECONÔMICO SE RELACIONAM, EVIDENCIANDO A CORRELAC̣ÃO DE FORÇAS QUE SE ESTABELECE ENTRE O GLOBAL E O LOCAL; OBJETIVOS DE PROMOÇÃO ECONÔMICA E DEMANDAS DE PROTEÇÃO SOCIOJURÍDICA; DESENVOLVIMENTISMO E DESENVOLVIMENTO; DIREITO DO E DIREITO AO DESENVOLVIMENTO. NO ÂMBITO DO ORDENAMENTO POSITIVO BRASILEIRO, A TEMÁTICA PODE SER ENCARADA DO PONTO DE VISTA DAS PREVISÕES LEGAIS ACERCA DA EXPLORAÇÃO DE RECURSOS HÍDRICOS E MINERAIS EM TERRAS INDÍGENAS, DECORRENTES DE TRATADOS INTERNACIONAIS SUBSCRITOS PELO PAÍS OU DO PRÓPRIO TEXTO CONSTITUCIONAL, LEVANDO A IDENTIFICAR FALHAS NA CONDUÇÃO E IMPLEMENTAÇÃO DESSES PROJETOS, ESPECIALMENTE QUANDO CONFRONTADOS COM PLATAFORMAS DE DIREITOS HUMANOS.

\section{PALAVRAS-CHAVE}

Desenvolvimento; Direitos Humanos; Grandes Projetos de Investimento; Hidrelétrica de Belo Monte; Direito AO CONSENTIMENTO LIVRE, PRÉVIO E INFORMADO.

\section{ABSTRACT}

THE CONSTRUCTION OF BELO MONTE DAM, IN NORTHERN BRAZIL, IS PRESENTED AS A FIELD OF REFLECTIONS ON DEVELOPMENT ISSUES, EMPHASIZING THE NEED TO EXAMINE DEVELOPMENT BASED ON ITS PLURALISTIC DIMENSIONS AND ON ITS ACHIEVEMENT BY DEMOCRATIC MEANS. THE ANALYSIS OF the so-CALled Major DeVElopment PRoJects, PARTicularly ON THE SECTOR OF POWER GENERATION, MAKES IT POSSIBLE TO UNDERSTAND HOW HUMAN RIGHTS AND ECONOMIC DEVELOPMENT ARE RELATED, SHOWING THE BALANCE OF FORCES THAT IS ESTABLISHED BETWEEN GLOBAL AND LOCAL; GOALS OF ECONOMIO PROMOTION AND CLAIMS OF SOCIO-JURIDICAL PROTECTION; DEVELOPMENTALISM AND DEVELOPMENT; THE DEVELOPMENT RIGHT AND THE RIGHT TO DEVELOPMENT. WITHIN BRAZILIAN LEGAL ORDER, THE THEMATIC CAN BE SEEN FROM A LEGAL STANDPOINT THAT CONSIDERS THE CONSEQUENCES OF WATER AND MINERAL RESOURCES EXPLOITATION INTO INDIGENOUS LANDS, WHICH RESULTS FROM BRAZILIAN SUBSCRIPTION OF INTERNATIONAL TREATIES OR FROM NATIONAL CONSTITUTIONAL TEXT ITSELF, LEADING TO IDENTIFY FAILURES IN THE CONDUCTION AND IMPLEMENTATION OF THESE PROJECTS, ESPECIALLY WHEN CONFRONTED WITH HUMAN RIGHTS PLATFORMS.

\section{KEYWORDS}

DEVELOPMENT; HUMAN RIGHTS; MAJOR DEVELOPMENT PROJECTS; BELO MONTE DAM; RIGHT TO FREE, PRIOR AND INFORMED CONSENT.

\section{INTRODUÇÃO}

A palavra desenvolvimento possui enorme elasticidade, podendo abranger diversos significados. Tomada no sentido de industrialização, é possível inferir que possui vínculos 
muito próximos com o tema da energia, cabendo afirmar que, ao longo dos tempos, a energia gerada a partir da exploração de recursos naturais foi transformada na base do funcionamento das sociedades desenvolvidas (aqui entendidas como sociedades industriais). Para Beck (1998, p. 13), a natureza, incluída e funcionalizada para os objetivos dos sistemas industriais, teria sido convertida em pressuposto insuperável desse modo de vida, fato que evidencia e justifica a intrínseca relação entre desenvolvimento, geração de energia e exploração dos recursos naturais.

Um grave problema que decorre dessa interdependência remete ao rápido crescimento da demanda global por novas fontes de energia e à diminuição de locais, no planeta, com potencialidades para tanto. $\mathrm{O}$ nexo entre necessidades econômicas e exploração energética estaria na raiz de expressivos conflitos atualmente existentes entre agentes políticos e agentes de mercado, responsáveis pelas decisões de efetivação dos grandes projetos de geração de energia, e a sociedade, nomeadamente as populações tradicionais e/ou povos indígenas que habitam e/ou dependem dos locais em cujo território esses recursos ainda estão disponíveis. É o que ocorre em países como Brasil, Chile, Bolívia, Venezuela e outros.

O conflito se dá por diversas razões. A mais comum decorre do fato de que, até mesmo em virtude de suas próprias concepções de desenvolvimento e da relação que estabelecem com os seus territórios, as populações e os povos habitantes das regiões ricas em recursos naturais reagem fortemente à intervenção do governo e/ou do mercado. Embora a visão utilitarista enxergue essas coletividades como guardiãs de riquezas naturais preciosas, deixadas pelo Estado na posse de tais domínios, os quais são, porém, passíveis de projetos de exploração (vez que a propriedade das riquezas do subsolo é da União), o fato é que, para as populações tradicionais, a importância do território (terra e recursos naturais) adquire caráter muito particular e relevante, por motivos culturais, sociais, religiosos e mesmo jurídicos. Para as culturas indígenas, tradicionalmente, a lógica da propriedade não é individual, mas coletiva; o território não possui valor exclusivamente monetário, posto fazer parte da vida e da morte. Assim, confrontados com os motivos econômicos da decisão de exploração, restam perplexos e incomodados, em meio ao paradoxo que envolve os temas do crescimento econômico e do desenvolvimento humano, marcado pela tensão entre tradição e progresso.

Neste sentido, o que para uns é progresso e construção do projeto nacional, para outros é restrição de direitos, destruição do local e redução, em médio prazo, de possibilidades globais. Dessa equação emerge a necessidade de ponderação entre crescimento-potência versus vulnerabilidade social e humana. Para os explorados, as decisões de investimento que atingem sua vida e cultura representam intervenções no curso natural dos acontecimentos, com implicações geofísicas (desmatamentos, mudanças nos veios de água, drenos e escoamentos naturais, entre outras); culturais (servidão de passagem em terrenos sagrados, perda de identidade, alterações 
comportamentais coletivas, miscigenação de culturas etc.); e humanas (perda de biodiversidade, transferência domiciliar, exposição a fenômenos urbanos como favelização, criminalização e marginalização), além do impacto que produzem no campo econômico, representados pela colonização e pela pilhagem de seu patrimônio, entre outras consequências. Para os exploradores, a viabilidade econômica do projeto é fundamental, preponderando a visão utilitarista dos resultados sobre quaisquer questionamentos acerca dos meios e dos procedimentos. Nessa ótica, a defesa da sustentabilidade ambiental e social parece se esgotar no contexto legal de execução da política ambiental do país, cumprida pela mera formalização de procedimentos administrativos e judiciais de avaliação de impactos, desde que levem em conta fatores como a redução de custos econômicos setoriais, a não interrupção de projetos que já consumiram vultuosas verbas, ${ }^{1}$ a valorização predial, a geração de energia para incremento de atividades comerciais e industriais, o crescimento do país e, por fim, a segurança nacional.

Em face do conflito que se estabelece entre a promoção do desenvolvimento, em seu aspecto marcadamente econômico, e a observância de direitos humanos e fundamentais, é possível identificar nítido paralelo entre o direito do desenvolvimento, ramo do direito econômico, com sede no ordenamento jurídico nacional, projeção nacional e matriz constitucional, e o direito ao desenvolvimento, ramo dos direitos humanos, de matriz positivada ou não, com sede nos documentos internacionais de proteção à dignidade das pessoas, e disposições recepcionadas ou (ainda) não em âmbito constitucional. No contexto desta última modalidade, nomeadamente no interior dos Direitos Econômicos, Sociais e Culturais (DESC), encarados como direitos humanos, a duplicação se apresenta sob a forma de novo desdobramento, como se aí fosse aberto um campo de tensão com a sobreposição dos direitos econômicos sobre os direitos sociais e culturais, de feições mais humanitárias. Destaca-se que é preciso instrumentalizar o aspecto econômico desses direitos em razão do que há de social e cultural neles, do contrário, não se realizam como direitos humanos (FEITOSA, 2011, p. 23).

Este artigo enfrenta o tema das dimensões plurais do desenvolvimento, destacando a construção da Hidrelétrica de Belo Monte, na região Norte do Brasil, como campo de reflexão sobre a questão da centralidade da geração de energia no funcionamento das chamadas sociedades industriais e pós-industriais e a relação desses processos com os direitos humanos. A vinculação entre o avanço das atividades de exploração dos recursos naturais para fins de geração de energia e o recuo dos direitos das pessoas que habitam os territórios atingidos pelos megaprojetos dá mostras da correlação de forças que se estabelece entre o global e o local; entre objetivos de promoção econômica e de proteção sociojurídica; entre o direito do e o direito ao desenvolvimento. Esses territórios, geralmente ocupados por populações tradicionais e/ou povos indígenas, transformam-se em palco de grandes embates políticos e jurídicos, que 
evidenciam a necessidade e o desafio de serem empreendidas análises mais aprofundadas em torno da relação entre desenvolvimento econômico e direitos humanos.

\section{i Desenvolvimento, energia e direitos humanos:}

AS INTERFACES DE UM NOVO TRINÔMIO

A energia é um dos insumos básicos do desenvolvimento, podendo-se mesmo dizer que sem energia não haveria desenvolvimento. Nesse sentido, energia e desenvolvimento caminham de mãos dadas, existindo inclusive um indicador de consumo de energia per capita que mede o nível de desenvolvimento dos países de acordo com o maior ou o menor consumo de energia por pessoa ${ }^{2}$ (GOLDEMBERG, 1998, p. 7). Entretanto, se a correspondência entre energia e desenvolvimento é assim tão evidente, a relação entre energia e direitos humanos apenas recentemente começou a ser enfrentada. Segundo Filmer-Wilson e Anderson (2005, p. 32), a questão da energia não tem sido tradicionalmente tratada no âmbito dos instrumentos internacionais de proteção aos direitos humanos porque, na verdade, o foco comum dos projetos de geração de energia tem se voltado mais para as ciências naturais e tecnológicas do que para as relações sociais e jurígenas. Assim, integrar a temática dos direitos humanos ao binômio energia-desenvolvimento significa, de antemão, mudar o foco essencialmente técnico da questão, pretendendo que projetos nessa área passem a posicionar o ser humano no centro de suas formulações, tarefa não exatamente fácil, dada a conjuntura de interesses envolvidos. No entanto, esta é a tendência mundial, no âmbito das novas discussões sobre medidas de desenvolvimento calcadas no chamado "desenvolvimento humano sustentável”.

Até o momento, a relação mais direta entre direitos humanos e energia tem-se dado pela via dos direitos procedimentais. Significa, por exemplo, que os direitos à informação, à participação, ao consentimento livre (prévio e informado), à não discriminação e a atenção aos grupos vulneráveis, entre outros, estabelecidos em instrumentos internacionais de direitos humanos, podem (e devem) ser aplicados nos casos relacionados a projetos que envolvam a geração de energia. Todavia, o conteúdo dos direitos humanos substantivos (não procedimentais), nesses casos, ainda possui fraco delineamento. Por tal razão, os conflitos e as situações de risco aos direitos humanos nos projetos que envolvem a geração de energia têm sido constantes e crescentes, em conjuntura abrangente, complexa e até mesmo estratégica, na medida em que a geração de energia apresenta estreita ligação com a questão da autonomia soberana dos Estados nacionais, sua produção de riquezas e inserção no cenário mundial, ao tempo em que coloca em xeque os temas da preservação de recursos naturais e da biodiversidade, fatores que, no contexto das análises econômicas, igualmente se projetam como fontes de divisas, com potencial para introdução estratégica do país em âmbito internacional, com a chamada "economia verde". 
Registre-se que os direitos processuais, incorporados ao tema dos grandes empreendimentos, encontram melhor moldura nos ordenamentos jurídicos nacionais, enquanto os direitos humanos recebem maior respaldo no âmbito das normativas internacionais. Entre um e outro, o modelo participativo de tomada de decisão das sociedades atuais, assim como a organização socioeconômica em geral, precisam ser aprimorados em termos de perspectivas democráticas. Bradlow (20002001) destaca que são inúmeros os atores envolvidos no complicado processo de tentar engendrar um modelo de tomada de decisão sobre o desenvolvimento que seja minimamente aceitável para todos os interessados e afetados pelos projetos de investimento. Pontua o autor que haveria duas visões idealizadas sobre a tomada de decisão no processo de desenvolvimento: a tradicional e a moderna. A visão tradicional seria aquela que enxerga o desenvolvimento como um processo econômico, onde as tomadas de decisão acerca de sua execução são focadas na elaboração e na construção de políticas e projetos que produzem crescimento econômico e autonomia internacional para o país, da forma mais eficiente possível. Já a visão moderna do desenvolvimento seria aquela que considera o desenvolvimento como processo integrado, estruturado em torno das dimensões sociais, econômicas, políticas, culturais e ambientais (BRADLOW, 2000-2001, p. 1534). Essas diferenças remetem, no fundo, à distinção entre desenvolvimento e desenvolvimentismo, tomado este como projeto singular e sequencial de crescimento ou acumulação de riquezas para posterior distribuição, e aquele como processo plural de recuperação de capacidades com vistas à distribuição das riquezas, oportunizando metas de solidariedade social e sustentabilidade ambiental.

Em tese, os propositores desta última tendência (moderna) entendem o desenvolvimento como episódio de transformação econômica, ambiental e social diante do objetivo maior de assegurar projeção ideal de distribuição de bem-estar, capaz de abranger as decisões sobre o gerenciamento dessas transformações. ${ }^{3}$ Não se trata aqui de afirmar que os defensores da visão dita “moderna” descuidem dos resultados dos processos de desenvolvimento, mas a sua preocupação primeira seria assegurar que a escolha dos resultados finais do desenvolvimento, entendido em feições plurais, seja capaz de incluir as prioridades e os anseios de todos os interessados relevantes, considerados no âmbito do processo de tomada de decisão.

Destaque-se a necessidade de ampla disponibilização de informações sobre o projeto, para que se tenham as bases adequadas de reflexão com a instalação do processo de consulta e participação dos interessados (BRADLOW, 2000-2001, p. 1545), como forma de assegurar maior poder de deliberação sobre os caminhos do desenvolvimento. É sobre isso o que trata Salomão Filho (2008, p. 49) quando assevera que a regulação econômica, incluído o setor da geração de energia, apresenta déficits reais de democracia. Para o autor, a regulação precisaria ser ampliada em torno de três elementos fundantes: a redistribuição dos benefícios do crescimento econômico; a 
ampliação da qualidade da informação, pela diluição dos centros de poder econômico e político, com a consequente difusão de informações, transformada em conhecimento, por toda a sociedade; e a cooperação, que alimenta a solidariedade e elimina o individualismo exacerbado dos agentes envolvidos, auxiliando a construção de processos econômicos dotados de maior legitimidade.

Interessante notar como se situa a democracia no interior dos dois modelos mencionados, vez que cada um revela distinta percepção sobre o fenômeno, além de ressaltarem (ambos) as diferenças entre governança democrática e tomada de decisão democrática. A governança democrática revela-se condizente com o modelo tradicional de desenvolvimento, vinculando as decisões levadas a efeito nos projetos de desenvolvimento apenas ao processo eleitoral, enquanto a tomada de decisão democrática, referente ao modelo moderno, relaciona tais decisões a um processo de consulta que não concentra a dimensão política do empreendimento no momento das eleições, reconhecendo a necessidade de permanência do processo democrático durante as fases de implementação do projeto. Para esta última concepção, democracia econômica significa processo em construção, em regime de participação e acompanhamento. Cabe recordar que os direitos de participação (participatory rights) resultam da tensão estabelecida entre os atores sociais reivindicativos, como, por exemplo, os movimentos ambientalistas e indígenas, e a arena política estatal, efetivando-se no acompanhamento cotidiano dos processos decisórios, o que revela a face mais intensa de uma democracia distinta daquela que se funda exclusivamente na representação (VENTURA, 2011).

Segundo Bradlow (2000-2001, p. 1539), o deslocamento da decisão democrática para o momento da eleição tende a ser problemático, posto que, no período eleitoral, o povo tem a oportunidade de mostrar sua preferência no contexto de uma série de amplas variáveis. As eleições, embora revestidas de caráter democrático, não são o veículo apropriado para a responsabilização de governos pelas decisões sobre os projetos de desenvolvimento que empreendam ou tenham empreendido. Eleitos democraticamente, os governos muitas vezes invocam a legitimidade da representação como pressuposto de autorização a priori para as ações perpetradas na persecução de seus projetos de "desenvolvimento". Esse entendimento permite concluir que a participação dos cidadãos nos rumos do desenvolvimento é feita de maneira deficiente, algumas vezes nem vindo a ocorrer, podendo-se mesmo admitir, com base em Bedjaoui (1987, p. 135), que o direito ao desenvolvimento teria adotado interpretação perigosa de seu significado quando se tornou aceito por muitos países e por alguns estudiosos como o direito que os Estados se autoatribuem para perseguir um modelo econômico de desenvolvimento específico.

Para Evans (2004, p. 30), o desenvolvimento democrático e deliberativo seria aquele baseado na participação popular quanto à definição de metas e à alocação de bens coletivos. O autor ressalta que as teorias sobre o desenvolvimento deixaram 
de se centrar apenas no tema da acumulação do capital, passando a abranger análises mais complexas acerca das instituições que tornam possível o desenvolvimento, lançando o desafio de serem envidados esforços no sentido do fortalecimento das instituições capazes de melhorar a habilidade dos cidadãos em fazer suas escolhas. A ampliação da base democrática de discussão do desenvolvimento é também abordada por Upendra Baxi (2003, p. 142), para quem "o desenvolvimento adequado identifica-se com o desenvolvimento participativo”, posto ser questionável a legitimidade de um tipo de desenvolvimento no qual poucas pessoas tomam todas as decisões.

Seguindo a mesma tendência, Orford (2001, p. 139) ressalta que o direito ao desenvolvimento é um direito participativo, pelo qual as pessoas podem controlar a direção do processo de desenvolvimento, mais do que simplesmente ser consultadas sobre projetos e políticas que já foram decididas. Donnelly (1999, p. 612), por sua vez, adverte que, a menos que desenvolvimento e democracia sejam entendidos e perseguidos de forma muito particular, podem colocar em risco os direitos humanos.

Existem, entretanto, algumas dificuldades com relação à implantação do processo participativo nos projetos de desenvolvimento. Pode ser identificada, entre outras, a necessidade de divulgação de informações corretas, vez que é importante, além de informar, fazer entender, deixando claros os objetivos e os impactos do empreendimento, ou seja, é preciso desembrulhar as políticas que estão ocultas ao projeto de desenvolvimento (RAJAGOPAL, 2006, p. 164), ação que, para os empreendedores, pode não se revelar consentânea com a aprovação pública do projeto, dificultando a participação verdadeiramente democrática nos rumos do desenvolvimento.

O fato é que a habilidade e a capacidade de escolher os rumos e caminhos a serem tomados por meio do desenvolvimento não podem ficar relegadas ao plano das ideias ou das intenções. Cabe recordar que o desenvolvimento foi normatizado como princípio constitucional na maioria dos Estados democráticos do mundo ocidental, transformando-se depois em imposição política para os países, a partir da ampliação de sua base econômica, mas dependendo, para se efetivar, em grande medida, de uma tomada de posição da sociedade e do alargamento dos canais de exercício da democracia (FEITOSA, 2009, p. 18).

No caso brasileiro, as polêmicas em torno da Hidrelétrica de Belo Monte têm produzido na sociedade debates que aquecem a discussão a respeito dos Grandes Projetos de Investimento (GPIs) e do tipo de desenvolvimento que tendem a perpetrar. Emergem daí campos opostos que defendem ou questionam o modelo centralizado de decisões, minimizando ou justificando a gravidade de danos não equacionados. Decerto que a construção de Belo Monte se dá no contexto de crises globais que abrangem devastação ambiental, insegurança alimentar e mudanças climáticas, financeiras e econômicas, em contraponto às demandas pela construção de uma agenda global sobre o clima e o meio ambiente, capaz de avançar no sentido de maior 
equilíbrio entre crescimento econômico, desenvolvimento humano e sustentabilidade (FEITOSA, 2009, p. 21). O fato é que a imposição desproporcional dos riscos ambientais sobre as populações mais vulneráveis (menos dotadas de recursos econômicos, políticos e informacionais) começa a ser encarada como fator da chamada "injustiça ambiental", no quadro de exigências de maior participação popular nos processos decisórios de empreendimentos em infraestrutura.

\section{Hidrelétricas E OS GRANDES PROJETOS DE INVESTIMENTO PARA GERAÇÃO DE ENERGIA}

Os GPIs são empreendimentos de enormes dimensões que movimentam grande volume de recursos econômicos, humanos e naturais. São normalmente levados a termo com forte atuação do Poder estatal, mas, na maioria das vezes, possuem o seu centro de decisão no poderio das grandes empresas, no fluxo do capital mundial e na dependência que os setores produtivos do mercado global possuem com relação aos recursos naturais. Essas corporações escolhem livremente os locais do planeta a explorar no intuito de transformar a matéria-prima em instrumento de seu processo produtivo. Embora movimentem recursos para uma determinada região, normalmente não contribuem para a redução das desigualdades que ocorrem no local, favorecendo, ao contrário, o acirramento de problemas sociais e ambientais nas regiões aonde se instalam (CRUZ e SILVA, 2010, p. 182).

No Brasil, a maioria dos GPIs tem sido incrementada em nome da industrialização e da soberania política, sob o aval do discurso da interiorização do desenvolvimento econômico e da garantia de segurança nacional. Foi o que ocorreu, por exemplo, com o modelo dos polos de desenvolvimento regionais. Nesse ambiente, os GPIs apresentam caráter pouco aberto à participação nas decisões que versam sobre sua implantação e subsídios estatais, acompanhado de ausências quanto aos impactos que as alterações socioeconômicas, culturais e ambientais causariam às regiões nas quais serão implantados.

A produção de energia elétrica nas sociedades contemporâneas vem normalmente acompanhada pela lógica econômica calcada na implantação de GPIs. Muitos deles entram em conflito com comunidades e grupos étnicos que habitam os locais de instalação do empreendimento, resultando em visíveis perdas para as formas de vida tradicionais, e causando empobrecimento a esses grupos, normalmente periféricos, tornando-os cada vez mais dependentes e vulneráveis. Os conflitos que se sucedem às decisões de GPIs, tendo como centro as comunidades tradicionais, têm acontecido em grande parte dos países da América Latina, como, por exemplo, nos casos da Hidrelétrica Hidroaysen na Patagônia Chilena; Hidrelétrica Chan-75, no Panamá; Hidrelétrica La Parota, no México, entre outros, que apontam a constante tensão entre o direito econômico do desenvolvimento e o direito humano 
ao desenvolvimento, na relação entre o nacional/internacional e o local/global de grupos em conflito.

O Brasil se insere nesta discussão, especialmente por ser um país naturalmente hidrelétrico, que possui numerosos rios com potencial para esse tipo de aproveitamento. ${ }^{4}$ Em muitos países, a água é utilizada para a geração de energia, no entanto, a participação da água na matriz energética mundial revela-se pouco expressiva e apresenta números decrescentes em relação à geração de energia elétrica, em razão do esgotamento das reservas mundiais que podem ser destinadas a esse fim (ANEEL, 2008). Segundo dados do Balanço Energético Nacional (EPE, 2012), 81,7\% da energia elétrica gerada no Brasil é proveniente de fonte hidrelétrica, sendo o restante produzido principalmente por termelétricas que empregam combustíveis fósseis ou nuclear. ${ }^{5}$

Considerados os benefícios, como o baixo preço econômico e a ausência de queima de combustíveis fósseis, um dos maiores problemas associados à geração de energia hidrelétrica reside no fato de que a construção das usinas hidrelétricas normalmente acarreta danos sociais e ambientais expressivos. Esses danos, na maioria das vezes, não são incorporados nas análises econômicas ou ambientais que precedem à construção das usinas (SINISGALLI, 2005, p. 5). Socialmente, os problemas apontados decorrem do fato de que a implantação desses empreendimentos não ocorre em espaços geográficos vazios, mas ocupam locais com população assentada, atingindo dinâmicas, relações, formas de trabalho, produção e reprodução enraizadas. As pessoas são retiradas de suas possessões contra a vontade, muitas vezes de forma violenta, além disso, convém lembrar que os canteiros de obra reproduzem a lógica de ocupação do espaço que, na ânsia por trazer "desenvolvimento" ao local, a qualquer custo, acaba acarretando desajustes sociais e violência, submetendo a população que vem em busca de trabalho à precariedade e à falta de acesso a infraestruturas adequadas. Assim, se o tema das hidrelétricas já era polêmico, a controvérsia se acirrou ainda mais diante do fato de que os atuais potenciais hidrelétricos do Brasil estão disponíveis em terras amazônicas, caracterizadas pelo delicado equilíbrio ecológico, nos locais aonde habitam populações tradicionais e povos indígenas, que se valem desses recursos naturais em equilíbrio para existirem.

\section{I O COMPlexo hidrelétrico de Belo Monte,}

\section{A INDÚSTRIA DE ALUMíNIO E OS POVOS INDÍGENAS}

A construção do Complexo Hidrelétrico (CHE) de Belo Monte está incluída no Programa de Aceleração do Crescimento (PAC), que tem como uma de suas três linhas mestras a energia, especificamente a geração e transmissão de energia elétrica. Na opinião de Pêgo e Campos Neto (2008, p. 16), o aspecto mais relevante dos investimentos a serem realizados pelo PAC remete à questão da redução do risco de déficit no abastecimento de energia elétrica no Brasil, em virtude do fato de que o Brasil teria passado na última década, especificamente em 2001, por situação de racionamento de energia 
elétrica, em razão do baixo regime hidrológico e da defasagem no investimento em novas fontes de energia.

O debate decorrente da crise questionou principalmente a capacidade dos investimentos em infraestrutura, não somente no tocante à questão da possibilidade de produzir crescimento econômico, mas também com relação ao beneficiário final dos investimentos do Estado (LEITÃO, 2009, p. 31), discutindo quem são os agentes verdadeiramente interessados na promoção desse tipo de desenvolvimento. Alguns autores afirmam que, de início, a proposta para o uso da energia gerada por Belo Monte abrangia a transmissão de parte dessa energia para a região Sudeste, especialmente São Paulo, incluída na rede de transmissão nacional, porém os altos custos da transmissão, aliados ao fato de que na maior parte do ano as linhas de transmissão ficariam com energia reduzida ou sem energia, mudaram os planos, que passaram a destinar a maior parte da energia para as indústrias de alumina e alumínio no próprio Pará (FEARNSIDE, 2009, p. 112).

Cabe ressaltar que a indústria de alumínio é basicamente voltada para exportação, ${ }^{6}$ cuja produção depende de intenso uso energético, ${ }^{7}$ gerando poucos empregos, além de beneficiar apenas um pequeno cartel de corporações. Pode-se constatar que os países periféricos, incluído o Brasil, sofrem os maiores impactos das etapas iniciais de produção do metal, que atinge diretamente as florestas tropicais e sua diversidade biológica e cultural (LIMA, 2009, p. 65-67), fato que reforça a tese de que a descentralização do foco do desenvolvimentismo em direção às regiões tidas como menos avançadas do Brasil é voltada essencialmente para a produção com vistas à exportação. Esse processo se realiza como atividade com baixo potencial de internalização de renda e de promoção de efetivo desenvolvimento das regiões nas quais se instalam (LEITÃO, 2009, p. 97).

Não há dúvidas de que a manutenção do modelo de crescimento intensivo em energia precisa ser questionada, havendo a necessidade de ser adotadas políticas energéticas direcionadas também para o lado da demanda, sem com isso negar o direito ao acesso de grande parte da população brasileira a esse bem (ROSA, 2007, p. 57). Na verdade, a luta em torno de Belo Monte parece elucidar que novos países industrializados ou grandes países emergentes, como no caso a China, a Índia e o Brasil, acabam por se envolver em indústrias que não mais existem em países pós-industriais, como a indústria de alumínio. No Japão, por exemplo, essa indústria foi fechada ainda nos anos 1980, passando o país a importar o alumínio, transformá-lo em chips, para então vendê-los por valor vinte vezes maior do que foi pago pelo alumínio utilizado (BERMANN, 2010).

Por outro ângulo, a aceitação desses empreendimentos pela população em geral pode ser vista em função do modo como normalmente governos e empresas conseguem transformar a imagem da ameaça em promessa de desenvolvimento, obstruindo informações claras e seguras sobre o que de fato está em jogo e sobre quais os resultados do 
projeto, positivos ou negativos. A importação de um modelo utilizado por países desenvolvidos, mas nestes já obsoleto, faz recordar o que Celso Furtado (1974) denunciava como a necessidade de se quebrar o "espelho do próspero", pugnando pela urgência de os países de terceiro mundo romperem com a imagem de progresso alienígena e construírem, cada um a seu modo, o seu próprio processo de desenvolvimento, entendido em sentido plural e inclusivo.

Em razão da estreita relação entre energia e desenvolvimento (industrial), compreende-se porque a base da economia industrial brasileira se assenta hoje sobre as hidrelétricas, que se utilizam das águas dos rios, recurso natural de fundamental importância para algumas populações tradicionais e para os povos indígenas. No caso de Belo Monte, trata-se do aproveitamento hídrico do rio Xingu, afluente importante do rio Amazonas e integrante da bacia Hidrográfica Amazônica, a maior do mundo. O Xingu percorre um trajeto de aproximadamente 2.000 quilômetros de extensão rumo ao interior da Amazônia, sendo responsável pela sobrevivência de populações tradicionais da região e diversos povos indígenas.

A ideia de barrar o rio Xingu não é recente. Data da década de 1970, quando o projeto do CHE de Belo Monte, anteriormente chamado Kararaô, foi programado como um dos seis barramentos previstos no estudo de inventário hidrelétrico do rio Xingu. ${ }^{8}$ Trata-se de obra vultosa, visto que Belo Monte será a terceira maior hidrelétrica no mundo, a maior brasileira, com obras de escavação de terras e de rochas em volume superior ao do Canal do Panamá, em meio à floresta amazônica. ${ }^{9}$

O projeto do CHE de Belo Monte será instalado na Volta Grande do Xingu, área geográfica na qual o rio apresenta uma alça, reserva indígena por excelência, existindo inclusive, nos arredores, grupos indígenas isolados ${ }^{10}$ (MAGALHÃES, 2009, p. 62). O Estudo de Impacto Ambiental do projeto distingue três grupos de povos indígenas na região do empreendimento: (i) o primeiro grupo engloba povos indígenas que vivem em área de influência direta (AID), incluídos nesse grupo os povos indígenas que habitam a Volta Grande do Xingu (Juruna do Paquiçamba, Arara da Volta Grande, Juruna do Km 17 e os Xikrin do Bacajá); (ii) o segundo grupo abrange os indígenas que vivem em área de influência indireta (AII), compreendendo os que vivem às margens do rio Xingu, acima da Volta Grande (Asurini do Koatinemo, Araweté, Parakanã) e às margens do rio Iriri (Arara, Arara de Cachoeira Seca e Kararaô); (iii) por fim, os indígenas citadinos, que de alguma forma ainda mantêm vínculos com seus povos e terras de origem.

O projeto percorre trajetória histórica polêmica, com inúmeras questões implicadas. É o caso da discussão sobre as maneiras pelas quais a hidrelétrica se insere no âmbito do crescimento da Amazônia; como são tomadas as decisões; os procedimentos de consulta aos povos indígenas afetados; a finalidade do uso da energia produzida; dúvidas com relação à sua viabilidade econômica, entre outras variáveis que colocam o empreendimento no foco de acalorados debates. 


\subsection{Aproveitamento de Recursos hídricos EM TERras indígenas NO Brasil:} PREVISÃO CONSTITUCIONAL DA OITIVA DAS COMUNIDADES INDÍGENAS Comparada às Cartas Magnas anteriores, a vigente Constituição Federal brasileira foi a que melhor reconheceu os direitos dos povos indígenas, resultado histórico alcançado em razão da intensa mobilização em prol desses diretos, ocorridas durante o processo constituinte. O art. 231 da CF reconhece as terras indígenas como bens da União, asseguradas na posse e usufruto vitalício e exclusivo dos indígenas, compreendendo as riquezas do solo, dos rios e dos lagos. Esse mesmo artigo atribui à União a competência para demarcar as terras tradicionalmente ocupadas pelos indígenas, em caráter permanente (BRASIL, 2010), o que é feito por meio de procedimento administrativo consignado em lei. A finalidade maior de tal previsão foi disciplinar a proteção das terras indígenas que vivem sob constante ameaça.

$\mathrm{O} \S 1^{\circ}$ do mencionado art. 231 define as terras tradicionalmente ocupadas pelos índios. Podem ser: aquelas por eles habitadas em caráter permanente; as utilizadas para suas atividades produtivas; as imprescindíveis à preservação dos recursos ambientais necessários a seu bem-estar; e as necessárias à sua reprodução física e cultural, segundo seus usos, costumes e tradições. Apesar da previsão constitucional protetiva, o texto legal expressamente reconhece, no $\S 3^{\circ}$ do mesmo artigo, que o aproveitamento dos recursos hídricos, incluídos os potenciais energéticos, em terras indígenas pode ser efetivado, desde que mediante autorização do Congresso Nacional, “ouvidas as comunidades afetadas". Significa que poderão ser efetivados os aproveitamentos em terras indígenas, desde que observados dois mandamentos: (i) a obtenção de autorização do Congresso Nacional; e (ii) a oitiva das comunidades afetadas (BRASIL, 2010).

Trata-se aqui de ponderar se tais previsões seriam tomadas conjuntamente, subsequente (ou seja, autorização do Congresso Nacional, depois de ouvidas as comunidades afetadas) ou separadamente (como dois processos distintos e independentes entre si). Além disso, especula-se em que medida se traduzem reais garantias para os povos indígenas. De antemão, é possível asseverar que os direitos à informação e à participação no processo político decisório ambiental, antes entendidos como macroprincípios jurídicos, passaram à categoria de direitos subjetivos, reconhecidos no âmbito do direito internacional e em vários ordenamentos nacionais, inclusive o brasileiro.

O poder de autorização, constitucionalmente atribuído ao Congresso Nacional, pode ser visto como função atípica deste, vez que sua função típica é legislar. Trata-se também de mecanismo integrante do sistema de freios e contrapesos, posto que, em sendo as terras indígenas da União, tornar-se-ia obrigatória a autorização de outro Poder Estatal para que o próprio Poder Executivo proceda ao aproveitamento desses recursos. Poderia ainda significar instrumento de participação indireta do povo brasileiro, tomado em sentido lato, na autorização da exploração, visto que, por meio de seus representantes, estaria concordando com a instalação de um empreendimento. 
Neste caso, a manifestação favorável do Congresso Nacional revestir-se-ia de caráter relativamente aceitável frente à população brasileira como um todo, cabendo, todavia, averiguar os efeitos dessa previsão no caso dos povos indígenas, especialmente por considerar sua condição de minorias étnicas, no conjunto da realidade brasileira.

Atente-se que uma das normas vigentes nas votações do Congresso Nacional é a regra da maioria, tanto em sua versão de maioria simples como de maioria qualificada. Segundo adverte Campilongo (1997, p. 38), a regra da maioria é a técnica de tomada de decisões coletivas "que maximiza a liberdade individual e assegura ampla e igual participação política dos cidadãos [...]", porém, "como regra majoritária, deve garantir a ampla liberdade também das minorias”, assim, saltam aos olhos as insuficiências de uma concepção de democracia que se identifica exclusivamente com a regra da maioria, vez que a democracia deve abranger também a proteção das minorias (CAMPILONGO, 1997, p. 52). Nesse contexto, a subsunção de direitos humanos de minorias à autorização da maioria traz claros limites de legitimidade.

Analisando-se a composição e os interesses do Congresso Nacional brasileiro, fica fácil perceber os motivos da ineficiência da representação dos povos indígenas nessa instância, problema que atinge não somente o Brasil, mas também outros países com presença de povos indígenas em seus territórios. A diferença é que em alguns países como, por exemplo, Colômbia ${ }^{11}$ e Finlândia, ${ }^{12}$ os Estados reconheceram mecanismos especiais de representação parlamentar indígena, medida que busca atenuar os déficits de representação, não sendo demais relembrar que a autodeterminação, um dos direitos reconhecidos internacionalmente aos povos indígenas, ${ }^{13}$ implica a abertura de vias de participação política por indivíduos e comunidades com base em suas distintas identidades. Young (1997, p. 349) argumenta em favor de um princípio especial de representação voltado aos grupos oprimidos e em desvantagem no processo de tomada de decisão política, em razão do problema decorrente da falha na sua representatividade. Para o autor, tais processos assegurariam a representação desses grupos de modo a permitir a efetiva expressão de seus interesses, geralmente ignorados, de forma que a perspectiva dos grupos minoritários relativizaria as posições do grupo majoritário, evitando que as ideias e posturas políticas da maioria sejam vistas como imparciais e universais, únicas a militar em prol do interesse geral. Nessa conjuntura, seria possível, ao menos em tese, entender a previsão de oitiva das comunidades afetadas como um daqueles mecanismos que buscam incorporar a visão do grupo minoritário ao processo decisório.

$\mathrm{Na}$ análise do caso concreto, os acontecimentos revelam que de fato houve a autorização do Congresso Nacional para a exploração do aproveitamento hidrelétrico de Belo Monte, por intermédio do Decreto Legislativo n. 788/2005. Até aí, o $\S 3^{\circ}$ do art. 231 da CF foi observado, inclusive em cumprimento ao inciso XVI do art. 49 da Constituição, que arrola como competência exclusiva do Congresso Nacional a autorização de exploração e aproveitamento de recursos hídricos em terras indígenas 
(BRASIL, 2010), no entanto, a parte seguinte, relativa à oitiva das comunidades afetadas, é passível de discussões.

Quando a casa legislativa aprovou, em tramitação recorde e em caráter de urgência ${ }^{14}$ o Decreto Legislativo n. 788/2005, autorizando o Poder Executivo a implantar o aproveitamento hidrelétrico (AHE) Belo Monte, não havia ouvido as comunidades indígenas afetadas. O texto do Decreto em questão estabeleceu como condição para a exploração dos recursos a realização de quatro estudos, na forma da lei: (i) Estudo de Impacto Ambiental; (ii) Relatório de Impacto Ambiental; (iii) Avaliação Ambiental Integrada da bacia do Rio Xingu; e (iv) estudo de natureza antropológica, atinente às comunidades indígenas localizadas na área sob influência do empreendimento, devendo, nos termos do $\S 3^{\circ}$ do art. 231 da Constituição Federal, ser ouvidas as comunidades afetadas (BRASIL, 2005).

Frente ao fato de que a oitiva não havia sido realizada, sustentou o Ministério Público Federal (MPF) que o processo legislativo gerador do Decreto n. 788/2005 teria vícios de ordem material. Não havia procedido à consulta com as comunidades indígenas afetadas, conforme previsão do art. 231, § $3^{\circ}$, da Constituição Federal de $88,{ }^{15}$ além de não dirimir a dúvida preliminar que dizia respeito à titularidade da atribuição da consulta, assim, o MPF questionava também se o processo de consulta deveria ser realizado pelo próprio Congresso Nacional, ou se poderia ser delegado ao empreendedor da obra, qual seja, o Poder Executivo, por intermédio do Instituto Brasileiro do Meio Ambiente e dos Recursos Naturais Renováveis (IBAMA).

Na sequência, o MPF acabou por concluir que o Congresso Nacional não poderia delegar a oitiva das comunidades envolvidas para terceira entidade, fato que maculava de inconstitucionalidade a delegação prevista no art. $2^{\circ}$ do Decreto Legislativo n. 788/2005. Para o MPF, se a previsão constitucional estabelece um mecanismo de participação de minorias no âmbito do Congresso Nacional, que é o órgão máximo do Poder Legislativo do Estado, um órgão ambiental ligado ao Poder Executivo (no caso, o IBAMA) não teria legitimidade para tal finalidade, devendo sua intervenção ser considerada nula (BRASIL, 2006a).

Em 2006, apreciando a ação movida pelo Ministério Público, por decisão da $5^{a}$ Turma do Tribunal Regional Federal da 1ª Região, o Decreto n. 788/2005 foi considerado inválido. Essa instância proibiu o IBAMA de realizar a consulta às comunidades indígenas, por entender ser atribuição exclusiva do Congresso Nacional, decidindo que, assim como a comunidade indígena não poderia ser substituída por outrem na consulta, o Congresso Nacional também não poderia delegar o ato para terceiros. De acordo com a decisão desse Tribunal, “o Congresso Nacional é quem consulta, porque é ele que tem o poder de outorgar a obra. Quem tem o poder tem a responsabilidade pelos seus atos" (BRASIL, 2006b).

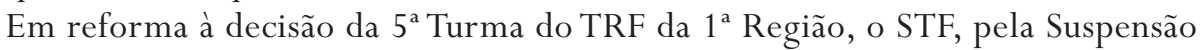
de Liminar n. 125, acompanhando o voto da Ministra Relatora, exaltou o caráter 
meramente programático do Decreto n. 788/2005. Considerou prematura e ofensiva à ordem administrativa a decisão judicial que impediu o Poder Executivo, pelo IBAMA, de proceder à realização de consulta às comunidades indígenas, sustentando que a proibição ao IBAMA de promover a consulta às comunidades indígenas, bem como as consequências dessa proibição no cronograma governamental de planejamento estratégico do setor elétrico do país, invadiriam a esfera de discricionariedade administrativa e repercutiria na formulação e na implementação da política energética nacional. Desse modo, o STF reconheceu como legítima a delegação da consulta e manteve válido o Decreto n. 788/2005 do Congresso Nacional, que autorizou a exploração do potencial hídrico sem a oitiva das comunidades indígenas afetadas (BRASIL, 2007).

Importante reconhecer que a previsão constitucional para a oitiva das comunidades, embora adote a tese da legitimidade da população afetada para tomar parte no processo decisório, restringe-se, na verdade, à expressão "ouvidas as comunidades afetadas”. À primeira vista, essa previsão reveste-se de caráter débil, restringindo-se a dizer que as comunidades serão ouvidas, sem qualificar o procedimento, o órgão responsável pelo processo, o momento da oitiva, a qualidade da oitiva nem as consequências resultantes da opinião dos “ouvidos”. Trata-se, pois, de instituto que merece (e requer) entendimentos mais aprofundados por parte da doutrina brasileira. A própria Ministra Relatora, reconhecendo o pouco tratamento do sistema jurídico brasileiro com relação à previsão, perfilhou a importância da realização do debate jurídico a respeito da natureza dessa consulta prevista em sede constitucional, "se política ou técnica”, reconhecendo, entretanto, não ser aquele o instrumento adequado para a realização de tal discussão (BRASIL, 2007).

Recorde-se, todavia, que a Constituição Federal recepciona no ordenamento jurídico nacional os tratados internacionais de direitos humanos dos quais o Brasil é parte $\left(\operatorname{art.} 5^{\circ}, \S \S 2^{\circ}\right.$ e $\left.3^{\circ}\right)$. Significa que, ao cumprir todas as formalidades de validação de um tratado internacional internamente, tal documento se integra ao ordenamento jurídico brasileiro, neste ponto, cabe salientar que o direito internacional dos direitos humanos previu a figura do consentimento livre, prévio e informado, que conceitua a participação dos povos afetados nas decisões que lhes atinjam, direta ou indiretamente.

Tal instituto político-jurídico foi recentemente afirmado na Declaração da ONU sobre o direito dos povos indígenas, em seu art. 32(2). Expressa que os Estados promoverão consultas e cooperarão de boa-fé com os povos indígenas interessados, por meio de suas próprias instituições representativas, para o fim de obter seu consentimento livre, prévio e informado, antes de aprovar qualquer projeto que afete as suas terras ou territórios e outros recursos, particularmente no que diz respeito ao desenvolvimento, à utilização ou à exploração de recursos minerais, hídricos ou de outro tipo. Ainda que não legalmente vinculante (soft law), o Brasil assinou esta Declaração da ONU, em 2007, recepcionando assim no direito brasileiro o direito ao consentimento livre, prévio e informado. 
Esse direito acrescenta adjetivos ao processo de consulta que busca qualificar o processo decisório, devendo ser feito em tempo anterior ao projeto de desenvolvimento. Prevê que o consentimento ocorra de maneira livre, ou seja, a partir do pronunciamento das próprias instituições indígenas, sem coações de qualquer espécie; ainda que seja fruto de um processo informado, ou efetivado de modo a facilitar o acesso a toda a informação necessária para que os sujeitos afetados possam bem compreender a natureza do projeto, seus variados impactos e detalhes. Em suma, esta figura procedimental reconhece aos povos indígenas o direito de participar nos processos de instalação de projetos que diretamente os atinjam e impactem.

Além da Declaração da ONU, outro documento de interesse ao tema é a Convenção n. 169 sobre Povos Indígenas e Tribais em países independentes da Organização Internacional do Trabalho (OIT), tratado juridicamente vinculante no Brasil (hard-law), que admite a consulta, nos termos do seu art. $6^{\circ}$ (1a), aos povos interessados, mediante procedimentos apropriados e, particularmente, por meio de suas instituições representativas, sempre que se tenham em vista medidas legislativas ou administrativas capazes de afetá-los diretamente. $\mathrm{O}$ art. $6^{\circ}$ (2) qualifica a forma como a consulta deve ser realizada: "efetuadas com boa-fé e de maneira apropriada às circunstâncias, com o objetivo de se chegar a um acordo e conseguir o consentimento acerca das medidas propostas”. Entende-se que, do histórico de construção e aprovação desses artigos, eles conferem o direito a ser consultado mais do que o direito ao veto (QUANE, 2005, p. 669), significando também que a Convenção n. 169 orienta para o alcance de um consenso, embora não estabeleça qualquer previsão sobre a atitude a tomar em caso de não se conseguir o acordo, ou seja, no caso de o povo optar pela não execução do projeto de desenvolvimento, por exemplo.

Somados os dois documentos internacionais mencionados à interpretação do $\S 3^{\circ}$ do art. 231 da Constituição Federal, podem ser trazidos ao ordenamento jurídico nacional contornos mais bem delineados para o caso do processo de consulta aos povos indígenas. Neste ponto, ecoam as palavras de Cançado Trindade (2000, p. 139) quando afirma que "o Judiciário nacional tem o dever de prover recursos internos eficazes contra violações tanto dos direitos consignados na Constituição como dos direitos consagrados nos tratados de direitos humanos [...]”. A análise conjunta dos instrumentos internacionais de direitos humanos ao texto da Constituição Federal brasileira deixa claro o caráter político, e não meramente técnico, do processo de consulta que visa assegurar aos indígenas a participação no processo de tomada de decisão de projetos de investimento que lhes afetem, não se restringindo a um espaço de mero informe sobre o teor técnico dos estudos de viabilidade do empreendimento.

O processo de consulta efetivamente realizado no caso do CHE de Belo Monte confundiu-se com as audiências públicas previstas para toda a população envolvida no âmbito do licenciamento ambiental. Todas elas foram realizadas pelo IBAMA. Assim, a oitiva prevista e destinada especificamente para os povos indígenas passou ao largo 
da realidade; por este motivo, a ausência da consulta relacionada à previsão internacional recebeu críticas dos organismos internacionais de direitos humanos, por exemplo, em relatório apresentado em Genebra, após missão ao Brasil, o relator especial da ONU sobre os povos indígenas destacou a preocupação com o fato de os povos indígenas não terem sido adequadamente consultados sobre a hidrelétrica de Belo Monte (ANAYA, 2010, p. 35).

Também a Comissão Interamericana de Direitos Humanos (CIDH) foi levada a se pronunciar sobre o caso, outorgando, em abril de 2011, medidas cautelares em favor dos membros das comunidades indígenas. Solicitou ao Governo Brasileiro que suspendesse imediatamente o processo de licenciamento do projeto, bem como interrompesse a realização de qualquer obra material de execução até que fossem realizados, entre outras recomendações, os processos de consulta, de maneira prévia, livre, informativa, de boa-fé, culturalmente adequada, e movida no sentido de alcançar um acordo justo, com relação a cada uma das comunidades indígenas afetadas (OEA, 2011).

Essa decisão da CIDH criou um incidente diplomático entre Brasil e a Organização dos Estados Americanos (OEA). Em nota do Ministério das Relações Exteriores, o Brasil considerou tais solicitações precipitadas e injustificáveis (BRASIL, 2011); na sequência, como retaliação, retirou a candidatura do ex-ministro da Secretaria de Direitos Humanos, Paulo Vannuchi, a uma vaga como representante do país perante a Comissão (PARAGUASSU, 2011), tendo ainda faltado à audiência perante a OEA no trâmite das medidas cautelares, a primeira ausência do Governo Brasileiro em convocações feitas pela Comissão até então.

Em julho de 2011, a CIDH reavaliou a medida cautelar com base na informação enviada pelo Estado e pelos peticionários, modificando o objeto da medida. Decidiu, em meio a outras recomendações substantivas, que o debate entre as partes relativo à consulta prévia e ao consentimento informado, no caso do projeto Belo Monte, havia se transformado em discussão sobre o mérito do assunto, o que transcenderia o âmbito do procedimento de medidas cautelares, e que, portanto, apreciaria a denúncia sobre a falta de consulta aos indígenas no pronunciamento sobre o mérito da petição (OEA, 2011), estando esse desdobramento ainda pendente de decisão.

\section{CONSIDERAÇÕES FINAIS}

A discussão sobre energia é assunto estratégico e relevante no mundo contemporâneo. Em última análise, o modo de produção das sociedades industriais aí encontra seus fundamentos, revelando intrínseca relação entre as ofensivas para a exploração dos recursos naturais em termos de geração de energia e as formas como impactam os territórios de populações tradicionais e povos indígenas.

O paradigma que baseia a exploração contínua de recursos naturais tem sido o de sua não finitude, pela compreensão da natureza como fonte inesgotável de recursos. 
A insustentabilidade desse paradigma coloca o imperativo de serem repensadas as bases de sustentação energética das sociedades industriais (e pós-industriais), acompanhadas por discussões em torno do tipo de desenvolvimento que perseguem, com inovações tecnológicas e comportamentais sendo postas ao serviço de novos modelos e formatos socioeconômicos de geração de energia.

A análise dos megaprojetos de investimentos, a partir da perspectiva das implicações para os direitos humanos dos povos indígenas, revela o impacto desproporcional que sofrem estes últimos, na medida em que tais direitos, além de não serem efetivamente reconhecidos, restam ainda marginalizados e minorados no processo de tomada de decisões dos GPIs. O crescente e ilimitado aumento das ações de exploração e a pressão pela extração dos recursos naturais provocam nas populações tradicionais e nos povos indígenas a revolta de suportarem preponderantemente os custos dessas atividades intensivas.

O caso da Hidrelétrica de Belo Monte ilustra o fato de como um GPI, destinado à geração de energia elétrica, acaba por atingir os povos indígenas, em diversas dimensões, de formas diretas e indiretas. Essas comunidades não são devidamente consideradas no âmbito de um tipo de desenvolvimentismo que prioriza o econômico imediato e discursa em nome do chamado "interesse nacional", nesse contexto, o Estado, seja por intermédio do Poder Judiciário, seja por meio do Legislativo ou do Executivo, deixa de observar e de implementar direitos humanos reconhecidos em instrumentos internacionais e nacionais de relevância. Não há dúvidas de que um dos principais problemas desse tipo de ação desenvolvimentista (não de desenvolvimento, porque desenvolvimento é outra coisa) está no enfoque exacerbado dado aos benefícios em longo prazo ou para a maioria, ignorando-se deliberadamente os prejuízos sofridos por comunidades minoritárias invisíveis, alijadas do processo, ou mesmo por comunidades amplas demais, por esta razão, também invisíveis, como as gerações presentes e futuras. Atente-se para prejuízos desconsiderados nos âmbitos locais e globais, contrapostos a propagados benefícios nas esferas regionais, nacionais ou mesmo internacionais (caso do comércio internacional, por exemplo).

Destaque-se que essa intervenção desenvolvimentista é obtida por meio da supressão dos costumes e práticas tradicionais, indo de encontro ao alcance dos objetivos do desenvolvimento sustentável. Trata-se da efetivação do direito do desenvolvimento, programado para o bem-estar econômico nacional e das maiorias, revelando um tipo de desenvolvimento excludente e espoliativo, que milita no sentido do endinheiramento privado e público, perdendo-se oportunidades importantes de expansão de modelos sustentáveis do uso dos recursos naturais. Ao eliminar os novos formatos de exploração dos recursos naturais, relativamente autônomos e sustentáveis, esse modelo desenvolvimentista acaba por normalmente lançar os grupos excluídos do processo para a categoria de marginalizados, empobrecendo formas sustentáveis de vida. 
As aldeias urbanas, supostamente civilizadas, vivem hoje no Brasil o problema do desemprego, da falta de escola, das drogas, da prostituição, entre outros. Sob este aspecto, tratar a temática do direito do desenvolvimento em contraposição ao direito ao desenvolvimento revela a preferência pelos aspectos econômicos unidisciplinares, encarados como prioridade a todo custo, em contraste com os ditames de alteridade, transversalidade e interculturalidade, típicos dos processos atuais de gestão responsável. A agressão a direitos humanos, em nome do desenvolvimento, falseia o discurso e atenta contra a sua substância plural e cultural. Desenvolvimento é algo que não pode se contrapor às culturas locais, tampouco ao meio ambiente global e, principalmente, não pode ultrapassar e desconsiderar direitos e garantias jurídicas. Tudo isso somente poderia ocorrer no âmbito de um Estado ditatorial, que se impusesse à força, subjugando os mais fracos, ou de um Estado débil, que se subordinasse ao poderio do mercado, sem capacidade de interagir com o futuro a médio e longo e prazo, largando à deriva os seus cidadãos. Não deve ser o caso do Brasil, que possui reais opções de concretização de um tipo de desenvolvimento capaz de colocar o país na dianteira da discussão de um novo padrão civilizatório para o mundo.

: ARTIGO APROVADO (15/05/2013) : RECEBIDO EM 23/01/2012

NOTAS

1 Em Projeto de Iniciação Científica - PIBIC, cadastrado e financiado pelo CNPq, intitulado "Desenvolvimento Econômico e Direitos Humanos no Brasil - Relações Críticas”, a equipe de pesquisa, sob a coordenação da pesquisadora-líder Maria Luiza de Alencar Mayer Feitosa, coletou a documentação judicial dos processos da hidrelétrica de Belo Monte e da construção da Ponte Rio Negro, a maior do Brasil, ambos na Amazônia brasileira. O estudo interpretativo das decisões judiciais evidencia a visão utilitarista do direito, em projeções do tipo law and economics.

2 Segundo Goldemberg (1998), nos países cujo consumo de energia comercial per capita esteja abaixo de uma tonelada equivalente de petróleo (TEP) por ano, as taxas de analfabetismo, mortalidade infantil e fertilidade total são altas, enquanto a expectativa de vida é baixa, ao contrário, quando o consumo aumenta, as condições sociais melhoram.

3 Podem ser citados aqui os cepalinos, com destaque para Raúl Prebish e Celso Furtado, além de autores como Amartya Sen, Ignacy Sachs entre outros.

4 O aproveitamento hidrelétrico no Brasil é da ordem de 30\%, sendo o Brasil o segundo maior consumidor de energia hidrelétrica do mundo (atrás da China) e o segundo no qual a hidroeletricidade ocupa o maior percentual na produção total de energia elétrica (atrás apenas da Noruega) (ANEEL, 2008).

5 A composição das fontes de geração de energia elétrica em 2011 ficou assim dividida: 81,7\% hidráulica; 6,5\% biomassa (lenha, bagaço de cana e outros); $0, \%$ eólica; 4,6\% gás natural; 2,5\% derivados de petróleo; $2,7 \%$ nuclear; $1,4 \%$ carvão e derivados (EPE, 2012). 
6 A produção de alumínio é basicamente para exportação. Em 2005, apenas seis países - EUA, China, Japão, Alemanha, Itália e França - foram responsáveis por $86 \%$ do consumo total do metal no mundo (ABAL apud LIMA, 2009, p. 66).

7 Em 2006, a produção de alumínio primário no Brasil consumiu cerca de 6\% de toda energia elétrica gerada no país (ABAL apud LIMA, 2009, p. 68).

8 Pela legislação brasileira, o estudo de inventário hidrelétrico é o primeiro passo para se planejar o aproveitamento de um potencial hidrelétrico com capacidade de geração superior a $30.000 \mathrm{Kw}$. Trata-se de uma etapa de estudos de engenharia em que se define o potencial hidrelétrico de uma bacia hidrográfica.

9 O CHE de Belo Monte coloca-se historicamente como sucessor de empreendimentos hidrelétricos amazônicos como Balbina, Samuel e Tucuruí, que produziram resultados problemáticos, a ponto de a Eletrobrás agora querer transformar os erros em lições, com o fito de orientar as construções das novas centrais hidrelétricas na Amazônia.

10 O EIA da obra é omisso quanto aos povos isolados, também chamados autônomos, que vivem ao redor da região. A Fundação Nacional do Índio (Funai) criou em janeiro de 2011 uma Terra Indígena (TI Ituna/Itatá) que abriga tais índios.

11 A Constituição colombiana reconhece o direito aos povos indígenas de participarem no Congresso (Senado e Câmara dos Deputados) através da Circunscrição Especial Indígena. Representantes indígenas que desejam ingressar no devem ter exercido autoridade tradicional em suas respectivas comunidades ou terem sido líderes de uma organização indígena.

12 O parlamento Sami (único povo indígena da Europa) é constituído por deputados Sami, sendo órgão responsável pela manutenção da cultura e línguas Sami e de certos deveres referentes ao estatuto dos Sami como povo indígena.

13 Cf. art. $3^{\circ}$ da Declaração da ONU de 2007: "Os povos indígenas tem o direito à autodeterminação. Em virtude deste direito determinam livremente sua condição política e perseguem livremente seu desenvolvimento econômico, social e cultural".

14 São palavras do congressista Luiz Otávio (PMDB-PA): “[...] estou na Casa há mais de sete anos, há projetos que estão aqui desde que cheguei e não saem das comissões, não andam. [...] Faz quatro dias que esse projeto [Autorização para Belo Monte] foi aprovado na Câmara e vamos aprová-lo aqui no Senado hoje. Eu nunca vi isso! Manifesto apenas a minha admiração... [...]" (Notas taquigráficas da sessão do Senado Federal que aprovou a proposição; extraídas do Agravo de Instrumento n. 2006.01.00.017736-8/PA do Tribunal Regional Federal da $1^{\text {a }}$ Região).

$15 \mathrm{Tal}$ questionamento foi, a princípio, apresentado pelo Procurador-Geral da República ao Supremo Tribunal Federal por meio de Ação Direta de Inconstitucionalidade - ADI 3.573/DF, que não foi conhecida no mérito, vez que os ministros julgaram que o instrumento jurídico escolhido não seria o correto.

\section{REFERÊNCIAS BIBLIOGRÁFICAS}

ANAYA. James Report by the Special Rapporteur on the situation of human rights and fundamental freedoms of indigenous peoples. Human Rights Council, set. 2010. Disponível em: <http://unsr.jamesanaya.org/PDFs/ Communications\%20report-FINAL.pdf>. Acesso em: 13 jan. 2012.

ANEEL, Atlas da energia elétrica do Brasil. 3. ed. Brasília: Agência Nacional de Energia Elétrica (ANEEL), 2008. Disponível em: <http://www.aneel.gov.br/visualizar_texto.cfm?idtxt=1689>. Acesso em: 6 jan. 2011. BAXI, Upendra. A evolução do direito ao desenvolvimento. In: SYMONIDER, J. (Org.). Direitos humanos: novas dimensões e desafios. Brasília: Unesco Brasil, Secretaria Especial dos Direitos Humanos, p. 139-160, 2003. BECK, Ulrich. La sociedad del riesgo: hacia una nueva modernidad. Buenos Aires: Paídós, 1998. BEDJAOUI, Mohammed. Some unorthodox reflections on the right to development. In: SNYDER, F.; SLINN, P. (Org.). International law of development: comparative perspectives. Milton Trading Estate: Abingdon, p. 87-116, 1987. 
BERMANN, Celio. A energia hidrelétrica não é limpa, nem barata. Ecodebate. Cidadania e meio ambiente, 2010. Disponível em: <http://www.ecodebate.com.br/2010/07/30/a-energia-hidreletrica-nao-e-limpa-nembarata-entrevista-com-celio-bermann/>. Acesso em: $28 \mathrm{dez} .2012$.

BRADLOW, Daniel. D. TheWorld Commission on Dams' contribution to the broader debate on Development Decision-Making 16 American University International Law Review. p. 1531-1572, 2000-2001.

BRASIL. Ministério das Relações Exteriores. Nota n. 142. Solicitação da Comissão Interamericana de Direitos Humanos da OEA de 5 de abril de 2011. Brasília, DF. Disponível em: <http://www.itamaraty.gov.br/salade-imprensa/notas-a-imprensa/solicitacao-da-comissao-interamericana-de-direitos-humanos-cidh-da-oea $>$. Acesso em: 4 jan. 2012. . Constituição da República Federativa do Brasil: promulgada em 5 de outubro de 1988. 44. ed. São Paulo: Saraiva, 2010 . . Supremo Tribunal Federal. Suspensão de Liminar: SL 125 PA. Requerente: União. Relatora: Min. Presidente (Ellen Gracie). Brasília, DF, 2007. . Ministério Público Federal/PA. Ação Civil Pública Ambiental, com pedido de liminar. Processo n. 2006.39.03.000711-8. Procuradoria da República do Município de Altamira. 2006a.

. Tribunal Regional Federal da $1^{a}$ Região. Agravo de Instrumento n. 2006.01.00.017736-8/PA. Agravante: MPF; Agravados: IBAMA; Eletrobrás; Funai; União. Relatora: Desemb. Fed. Selene Ma. de Almeida. Brasília, DF, 2006b.

Decreto Legislativo n. 788, 13 de julho de 2005. Disponível em: <http://www6.senado.gov.br/ legislacao/ListaTextoIntegral.action?id=231371>. Acesso em: 29 dez. 2011.

CAMPILONGO, Celso Fernandes Direito e democracia. São Paulo: Max Limonad, 1997.

CANÇADO TRINDADE, Antonio Augusto. A proteção internacional dos direitos humanos e o Brasil (1948-1997): as primeiras cinco décadas. 2. ed. Brasília: Ed. Universidade de Brasília. 2000.

CRUZ, Carla Buiatti; SILVA, Vicente de Paulo. Grandes projetos de investimento: a construção de hidrelétricas e a criação de novos territórios. Sociedade e Natureza, 22 (1), Uberlândia, p. 181-190, 2010.

DONELLY, Jack. Human rights, democracy and development. Human Rights Quarterly: The Johns Hopkins University Press, p. 608-632, 1999, v. 21.

EPE (Brasil). Balanço energético nacional 2012: ano base 2011. Empresa de Pesquisa Energética - Rio de Janeiro: EPE, 2012. Disponível em: < https://ben.epe.gov.br/downloads/Resultados_Pre_BEN_2012.pdf >. Acesso em: 04 jul. 2013.

EVANS, Peter. Development as institutional change: the pitfalls of monocropping and the potentials of deliberation. Studies in Comparative International Development, v. 38, n. 4. p. 30-52, 2004.

FEARNSIDE, Philip. O novo EIA-RIMA da Hidrelétrica de Belo Monte: Justificativas goela abaixo. In: SANTOS, S. M. S. B. M.; HERNANDEZ, F. DE M. (Orgs.). Painel de especialistas: Análise Crítica do Estudo de Impacto Ambiental do Aproveitamento Hidrelétrico de Belo Monte. Belém, p. 108-117, 2009. Disponível em:

< http://www.internationalrivers.org/files/attached-files/belo_monte_pareceres_ibama_online_3.pdf > . Acesso em: 19 out. 2010.

FEITOSA, Maria Luiza Alencar Mayer. Direito econômico da energia e do desenvolvimento - superando a visão tradicional. In: FEITOSA, M. L. A. M.; PEREIRA, M. M. F. Direito Econômico da Energia e do Desenvolvimento. Ensaios Interdisciplinares. São Paulo: Conceito, 2011.

Coimbra, 2009

Desenvolvimento econômico e direitos humanos. Separata do Boletim de Ciências Econômicas LII.

FILMER-WILSON, Emilie; ANDERSON, Michael. Integrating Human rights into energy and environment programming: a reference paper. Nova York: PNUD, 2005. Disponível em: <http://www.beta.undp.org/content/undp/en/home/ librarypage/environment-energy/local_development/integrating-human-rights-into-energy-and-environmentprogramming.html>. Acesso em: 19 jan. 2011.

FURTADO, Celso O mito do desenvolvimento econômico. Rio de Janeiro: Paz e Terra, 1974.

GOLDEMBERG, José. Energia e desenvolvimento. Estudos Avançados, v. 12, n. 33. São Paulo, maio/ago. 1998.

LEITÃO, Karina Oliveira. A dimensão territorial do Programa de Aceleração do Crescimento: um estudo sobre o PAC no Estado do Pará e o lugar que ele reserva à Amazônia no desenvolvimento do país. Tese (Doutorado) Faculdade de Arquitetura e Urbanismo, Universidade de São Paulo, São Paulo, 2009.

LIMA, Dumara Regina; MOTA, José Aroudo. - A produção do alumínio primário na Amazônia e os desafios da sustentabilidade ambiental. Boletim Regional, Urbano e Ambiental. Instituto de Pesquisa Econômica Aplicada IPEA, p. 65-70, jul 2009.

MAGALHÃES, Antonio Carlos. Aproveitamento hidrelétrico do Rio Xingu. Usina de Belo Monte. Análise de Estudo de Impacto Ambiental Povos Indígenas. In: SANTOS, S. M. S. B. M.; HERNANDEZ, F. de M. (Orgs.). Painel de especialistas: análise crítica do estudo de impacto ambiental do aproveitamento hidrelétrico de Belo Monte. 
Belém, p. 61- 69, 2009. Disponível em: < http://www.internationalrivers.org/files/attachedfiles/belo_monte_pareceres_ibama_online_3.pdf> Acesso em: 19 out. 2010.

OEA, Comissão Interamericana de Direitos Humanos. Medida Cautelar n. 382/10. Comunidades Indígenas da Bacia do Rio Xingu. Pará, Brasil, 2011. Disponível em: <http://www.cidh.org/medidas/2011.port.htm>. Acesso em: 4 jan. 2012.

ORFORD, Anne. Globalization and the Right to Development. In: ALSTON, P. (Ed.). People's Rights. Oxford: Oxford University Press. p. 127-184, 2001.

PARAGUASSU, Lisandra. Brasil retira candidatura de Vannuchi para vaga na OEA. 12 de abril de 2011. Disponível em: <http://www.estadao.com.br/noticias/nacional, brasil-retira-candidatura-de-vannuchi-para-vaga-naoea,705426,0.htm>. Acesso em: 4 jan. 2012.

PÊGO, Bolívar; CAMPOS NETO, Carlos Alvares da Silva. O PAC e o setor elétrico: desafios para o abastecimento do mercado brasileiro (2007-2010). Texto para discussão n.1.329. IPEA. Brasília, 2008.

QUANE, Helen. The rights of Indigenous Peoples and the Development Process. Human Rights Quarterly 27. The Johns Hopkins University Press. p. 652-682, 2005.

RAJAGOPAL, Balakrishnan. Counter-hegemonic international law: rethinking human rights and development as a third world strategy. Third World Quarterly, issue 5, p. 148-169, 2006.

ROSA, Luiz Pinguelli. Geração hidrelétrica, termelétrica e nuclear. Estudos Avançados 21 (59), p. 39-58, 2007. SALOMÃO FILHO, Calixto. Regulação da atividade econômica - princípios e fundamentos jurídicos. 2. ed. São Paulo: Malheiros, 2008.

SINISGALLI, Paulo Antonio Almeida. Valoração dos danos ambientais de hidrelétricas: estudos de caso. Tese (Doutorado) - Universidade Estadual de Campinas Instituto de Economia. Campinas: [s.n.], 2005.

VENTURA, Victor Alencar Mayer. Jurisdição e direitos participativos: o papel do judiciário na implementação do dever de consulta prévia. In: II Encontro PROCAD UFAL-UFPE-UFPB: O judiciário e o discurso dos direitos humanos, 2012, Recife. Memória Digital do II Encontro PROCAD UFAL-UFPE-UFPB. Recife: Editora Universitária UFPE, 2011. p. 429-447.

YOUNG, Iris Marion. Deferring group representation. In: SHAPIRO, I.; KYMLICKA, W. (Ed.). Ethnicity and Groups Rights. New York: New York University Press, p. 349-376, 1997.

\section{Centro de Ciências Jurídicas Universidade Federal da Paraíba Cidade Universitária (Campus I) - 58051-900 João Pessoa - PB - Brasil ffranco.cristinalagmail.com}

Centro de Ciências Jurídicas Universidade Federal da Paraíba Cidade Universitária (Campus I) - 58051-900 João Pessoa - PB - Brasil mluizalencarlagmail.com

\section{Fernanda Cristina de Oliveira Franco}

Doutoranda em Direitos Humanos e Desenvolvimento pelo Programa de Pós-Graduação em Clências Jurídicas da UFPB

Mestre em CIÊnCIAS JuRídicAs PElo MESMO PROgRama Graduada em Direito Pela Faculdade de Direito da USP

\section{Maria Luiza P. de Alencar Mayer Feitosa}

Pós-doutorado em Direito PELA UFSC

DOUTORA EM CIÊNCIAS JURÍDICO-ECONÔMICAS pela Universidade de Coimbra, Portugal

Professora permanente do Programa de Pós-Graduação EM CiênCIAS JuRídicAS dA UFPB Diretora do CEnTro dE CIÊnCIAS JurídicAS dA UFPB 